non-binomial, unsystematic popular compilation.

The volume is effusively dedicated to "Wilhelmo VI Hessio Landgravio," whose titles and virtues his "devotus cliens" expounds at length.

\section{David Starr Jordan}

\section{SPECIAL ARTICLES}

ON A METHOD OF ESTIMATING THE NUMBER OF GENETIC FACTORS CONCERNED IN CASES OF BLENDING INHERITANCE

IN the early days of rediscovered Mendelism Bäteson ${ }^{1}$ suggested the idea that what was then known as blending inheritance might be a variety of Mendelism in which dominance was wanting, but in which several or many independent factors were involved. This suggestion was found to be in good agreement with much experimental work on quantitative characters subsequently carried on by NilssonEhle, Tammes, Emerson and East, and others. It is now generally accepted as the most probably correct explanation of all varieties of intermediate or blending inheritance. Accepting this as a working hypothesis, have we any means of discovering how many factors are involved in cases of blending inheritance? Surely the number must be very different in different cases.

Noteworthy features of blending inheritance are the following: (1) $\mathrm{F}_{1}$ is intermediate between the pure parental races, but not more variable than the more variable parent. (2) $F_{2}$ is likewise intermediate in character but is more variable than $\mathrm{F}_{1}$ or either parent. (3) In $F_{3}$ and subsequent generations the varia- bility decreases from the maximum suddenly attained in $\mathrm{F}_{2}$.

In all varieties of inheritance, whether typically Mendelian or blending, the maximum variability is to be found in the $\mathrm{F}_{2}$. generation. In ordinary Mendelian inheritance we are able to detect the number of genetic factors concerned by the number of phenotypes which are distinguishable in $\mathrm{F}_{2}$ and by their numerical proportions. The $F_{1}$ generation is in strong contrast with the $\mathrm{F}_{2}$ generation to which it gives rise, for $F_{1}$ is of a single type, if the parent races were pure.

In blending inheritance also, it is the $F_{2}$ generation which affords a clue to how many genetic factors are involved, not by the formation of clearly distinguishable types (for there is but one), but by the amount of the variability of that single type in $F_{2}$ as compared with $F_{1}$.

To make this clear, let us consider the numerical series commonly employed, by expositors of the multiple factor hypothesis, for explaining the increased variability of $F_{2}$ in blending inheritance. If two pure races differ from each other by a single genetic factor (which does not show the phenomenon of dominance), and if these two pure races are crossed, $\mathrm{F}_{1}$ will be intermediate. $\mathrm{F}_{2}$ will also be intermediate in part, but the parental classes will also reappear, and there will thus be three distinguishable classes in $F_{2}$, which correspond with the two parental types and the $F_{1}$ type respectively. The classes will be numerically as $1: 2: 1$, as in the familiar case of the blue Andalusian fowl.

Now suppose that the pure parent races dif-

TABLE I

$F_{2}$ Distributions in Size Classes, when Inheritance is Blending and Involves from One to Six Independent and Equivalent Factors

\begin{tabular}{|c|c|c|c|c|c|c|c|c|c|c|c|c|c|c|}
\hline \multirow[b]{2}{*}{ Factors } & \multicolumn{13}{|c|}{ Class Magnitudes (Top Row) and Frequencies (Below) } & \multirow{2}{*}{$\begin{array}{l}\text { Standard } \\
\text { Deviation }\end{array}$} \\
\hline & 1 & 2 & $\mathbf{3}$ & 4 & 5 & 6 & 7 & 8 & 9 & 10 & 11 & 12 & 13 & \\
\hline 1 & 1 & & & & & & 2 & & & & & & 1 & $\sqrt{18}$ \\
\hline 2 & 1 & & & 4 & & & 6 & & & 4 & & & 1 & $\sqrt{9}$ \\
\hline 3 & 1 & & 6 & & 15 & & 20 & & 15 & & 6 & & 1 & $\sqrt{6}$ \\
\hline 6 & 1 & 12 & 66 & 220 & 495 & 792 & 924 & 792 & 495 & 220 & 66 & 12 & 1 & $\sqrt{3}$ \\
\hline
\end{tabular}

1 Report I. to the Evolution Committee of the Royal Society, London, 1902. 
fer by two independent but equally powerful factors, neither of which shows dominance. $\mathrm{F}_{1}$ will again be intermediate but of a single type and not more variable than either pure parent race. But $F_{2}$, by recombination of the two differential factors, will now consist of five graded types, two of which correspond with the parental types, while the remaining three are found in the intervening region at equally spaced intervals. If the several graded types are readily distinguishable one from another, they will be found to occur in the proportions $1: 4: 6: 4: 1$. But if the types are so close together in appearance as not readily to be distinguishable, the distribution will resemble a probability curve.

Further, if three independent but equivalent factors are involved in a cross where dominance is wanting, the $\mathrm{F}_{2}$ classes will number seven and their frequencies will be as $1: 6: 15: 20: 15: 6: 1$.

Now, suppose that in these several hypothetical cases, the character under investigation is size, and that the amount of difference in size between the parents is in every case the same; let us say for convenience, 12 units (inches, pounds, or whatever the case may be). Then the several classes of individuals of which $\mathrm{F}_{2}$ is composed will have the class magnitudes and frequencies shown in Table $I$.

For distributions, such as those shown in Table I., we can readily calculate standard deviations, which measure the variability of each array. See the last column of Table I. It will be observed that the standard deviation falls off rapidly as the number of factors involved increases. Inspection of the column headed "standard deviation" in Table I. will allow one to arrive at the law of decrease of the standard deviation with corresponding increase of factors. It is evident that as the number of factors is doubled, the standard deviation is halved under the radical sign. In other words, to reduce the standard deviation by one half, the number of factors must be increased four fold. With this point in mind one can extend as far as is desired the columns in Table I. headed "factors" and "standard deviation."
In Table I. the difference between the parents is assumed to be 12 units and the standard deviation is expressed in terms of those units. To give the table a general form, we might suppose the difference between the parents to be one unit. The standard deviation would then be only one twelfth as great. It is so given in Table II., wherein only the columns "factors" and "standard deviation" are entered from Table I.

TABLE II

Standard Deviation of $F_{2}$ Expressed in Per Cent. of the Difference between the Parent Races

\begin{tabular}{r|c|c|c|c|c|c|c}
\hline Fac- & $\begin{array}{c}\text { Stand- } \\
\text { ard } \\
\text { Devia- } \\
\text { tion }\end{array}$ & $\begin{array}{c}\text { Fac- } \\
\text { tors }\end{array}$ & $\begin{array}{c}\text { Stand- } \\
\text { ard } \\
\text { Devia- } \\
\text { tion }\end{array}$ & $\begin{array}{c}\text { Fac- } \\
\text { tors }\end{array}$ & $\begin{array}{c}\text { Stand- } \\
\text { ard } \\
\text { Devia- } \\
\text { tion }\end{array}$ & $\begin{array}{c}\text { Fac- } \\
\text { tors }\end{array}$ & $\begin{array}{c}\text { Stand- } \\
\text { ard } \\
\text { Devia- } \\
\text { tion }\end{array}$ \\
\hline 1 & 35.35 & 13 & 9.75 & 44 & 5.32 & 144 & 2.94 \\
$\mathbf{2}$ & 25.00 & 14 & 9.50 & 48 & 5.10 & 160 & 2.79 \\
$\mathbf{3}$ & 20.41 & 15 & 9.12 & 52 & 4.87 & 176 & 2.66 \\
4 & 17.67 & 16 & 8.81 & 56 & 4.75 & 192 & 2.55 \\
5 & 15.81 & 17 & 8.53 & 60 & 4.56 & 208 & 2.43 \\
6 & 14.43 & 18 & 8.33 & 64 & 4.40 & 224 & 2.37 \\
7 & 13.33 & 20 & 7.90 & 68 & 4.26 & 240 & 2.28 \\
8 & 12.50 & 24 & 7.21 & 72 & 4.16 & 256 & 2.20 \\
9 & 11.78 & 28 & 6.66 & 80 & 3.95 & 272 & 2.13 \\
10 & 11.18 & 32 & 6.25 & 90 & 3.60 & 288 & 2.08 \\
11 & 10.64 & 36 & 5.89 & 112 & 3.33 & 320 & 1.97 \\
12 & 10.20 & 40 & 5.59 & 128 & 3.12 & 384 & 1.80 \\
\hline
\end{tabular}

In the foregoing discussion, it has been assumed that the parent races were completely homozygous and so deviod of genetic variability. If this were true of the parents, it would also be true of $F_{1}$. In that case whatever variability was exhibited by the parents or $\mathrm{F}_{1}$ would be non-genetic. Under like environment $\mathrm{F}_{2}$ would be expected to show a like amount of non-genetic variability. Hence in estimating the genetic variability of $F_{2}$ one would have to deduct from the total observed variability of $\mathrm{F}_{2}$ an amount equal to the observed (non-genetic) variability of $F_{1}$.

In practise one would proceed as follows. First find the difference between the standard deviations of $F_{1}$ and $F_{2}$. Divide this by the difference between the parental means (the respective means of the two pure parent races). Multiply the quotient by 100 . Now look in Table II. for the nearest corresponding number in the column "standard deviation." Op- 
posite this will be found the number of factors indicated.

Let us take a specific example. Emerson and East ${ }^{2}$ (1913, p. 59) studied (among other quantitative characters) the inheritance of weight of seed in crosses of two varieties of maize. The mean weight of a seed in one parent variety was 2.7 grams; in the other variety, it was 8.3 grams, a difference of 5.6 grams. The seeds of $\mathrm{F}_{1}$ plants had a mean weight of 4.6 grams and a standard deviation in weight of .639 grams. The mean seed weight of $\mathrm{F}_{2}$ plants was 6.0 grams and the standard deviation for $F_{2}$ was 1.17 grams. The difference between the standard deviations of $\mathrm{F}_{1}$ and $\mathrm{F}_{2}$ is $1.17-.639=.531$ grams. This is to be divided by the difference between the parental means, which was 5.6 grams. Now .531/5.6 $=.0948$, which multiplied by 100 gives 9.48 per cent. Looking in the column "standard deviation" in Table II., we find the indicated number of factors to be 14 .

Emerson and East made two other crosses between these same varieties of maize, but used different individuals as the parents in each cross. The results for the other two crosses may be compared with the case just discussed to test the reliability of the method. In one case, the standard deviation of $\mathrm{F}_{2}$ was 1.089, making the difference between $\mathrm{F}_{1}$ and $\mathrm{F}_{2} .45$. Now $(.45 / 5.6) \times 100=8.03$ per cent., which corresponds with the result expected from about 19 . factors. In the other case the standard deviation of $F_{2}$ was 1.23, making the difference between $\mathrm{F}_{1}$ and $\mathrm{F}_{2}$.591. But 2 "The inheritance of quantitative characters in maize," Res. Bull., 2, Agr. Exp. Station, Nebraska.
(.591/5.6) $\times 100=10.55$ per cent., indicating 11 factors. The three different lots of $F_{2}$ individuals thus indicate the factorial differences between the parents crossed to have been in one case, 11 factors; in a second case, 14 factors; and in a third case, 19 factors. It is rather probable that the parent races were not homozygous, maize rarely is. But the indicated mean difference between the parent races would be about 15 factors.

It is evident that the method has some serious limitations in its applicability. It applies perfectly only to cases in which the parents are genetically pure, that is, are homozygous for all factors affecting the character under investigation. Such material is rarely met with even in self fertilizing plants. If either of the parent races is in any degree variable genetically (heterozygous), $F_{1}$ will be variable in like degree. This will tend to decrease the difference in variability between $F_{1}$ and $F_{2}$ and so to increase the indicated number of factorial differences between the parents. This difficulty can be offset in part by raising an $\mathrm{F}_{2}$ generation derived from all classes of $F_{1}$ in the proportion of their occurrence. It is obvious that when a variable $F_{1}$ is obtained, various classes of $F_{1}$ individuals should be tested as to their genetic character, and if they are found to be genetically diverse, each should have proportionate representation in the $F_{2}$ population.

The theory of multiple factors in blending inheritance assumes that each factor is equal to every other factor in its influence on the character affected. It is improbable that this is strictly true, but no other assumption will

TABLE III

Estimation of the Number of Genetic Factors Influencing Weight Involved in Crosses of Certain Races of Rabbits

\begin{tabular}{|c|c|c|c|c|c|}
\hline Cross & $\begin{array}{c}\text { Standard } \\
\text { Deviation } \\
\mathrm{F}_{2}\end{array}$ & $\begin{array}{l}\text { Standard } \\
\text { Deviation } \\
\mathrm{F}_{1}\end{array}$ & $\begin{array}{l}\text { Difference } \\
\text { between } \\
\mathrm{F}_{2} \text { and } \mathrm{F}_{1}\end{array}$ & $\begin{array}{c}\text { Difference } \\
\text { between } \\
\text { Means of } \\
\text { Parent } \\
\text { Races }\end{array}$ & $\begin{array}{l}\text { Factors } \\
\text { Indicated }\end{array}$ \\
\hline $\begin{array}{l}\text { Pólish } \times \text { Himalayan } \ldots \ldots \ldots \ldots \ldots \ldots \ldots \ldots \\
\text { Himalayan } \times \text { Flemish } \ldots \ldots \ldots \ldots \ldots \ldots \ldots \\
\text { Polish } \times \text { Flemish } \ldots \ldots \ldots \ldots \ldots \ldots \ldots \ldots\end{array}$ & $\begin{array}{l}233 \\
230 \\
257\end{array}$ & $\begin{array}{l}212 \\
162 \\
198\end{array}$ & $\begin{array}{l}21 \\
68 \\
59\end{array}$ & $\begin{array}{r}471 \\
1,725 \\
2,196\end{array}$ & $\begin{array}{r}56 \\
80 \\
176\end{array}$ \\
\hline
\end{tabular}


permit of a general treatment of blending inheritance. If one attempts to apply to each case a scheme of specially weighted factors, as Punnett has done for size inheritance in fowls and rabbits, he proves nothing except the fact that a factorial explanation of his results is possible, for by properly weighting factors and assuming that some inhibit the action of others, one can fit to his observations a scheme involving either few or many factors. If one factor really has an influence greatly superior to that of other factors in a case of blending inheritance, this will be seen in the production of asymmetrical or multimodal variation polygons in $F_{1}$ and $F_{2}$. If, when adequate numbers are produced, the variation curves of $F_{1}$ and $F_{2}$ are both smooth, it is certain that no genetic factor of predominant influence is involved in the case, but that several or many factors substantially equal in influence are concerned. Whether many or few can perhaps be ascertained by the method suggested in this paper.

I have recently applied it in the study of weight inheritance in crosses between races of rabbits differing in size, with the following results. Three races of rabbits were crossed in all possible ways. The average size of the smallest race, Polish, was 1,404 grams; of the second race, Himalayan, it was 1,875 grams; of the third race, Flemish, it was 3,600 grams. The number of factors indicated as differentiating the races in weight is in the order of magnitude of the differences between the races. See Table III. But the number of factors indicated as differentiating the smallest race from the largest (Polish from Flemish) is apparently too great, since it exceeds the sum of the differences in number of factors indicated as existing in the other two crosses. It is perhaps not to be expected that results more than approximately correct would be given by this method, unless fairly large numbers of both $F_{1}$ and $F_{2}$ individuals have been studied. In the rabbit crosses, the numbers of $F_{1}$ individuals studied were 16,25 , and 27 , respectively. The $\mathrm{F}_{2}$ numbers were 50,62 , and 112. The results obtained are sufficient to indicate the probability that in the Polish $\times$ Himalayan cross, 50 or more factors are involved, and that the crosses with the largest race, Flemish, involve two or three times as many factorial differences. A fuller discussion of this case will be published later.

W. E. Castle

Bussey Instritumion, May 27, 1921

\section{THE UTAH ACADEMY OF SCIENCES}

THE fourteenth annual convention of the Utah Academy of Sciences met in the physies lecture room of the University of Utah, Salt Lake City, on Friday evening, April 1, 1921, and continued for three sessions, closing Saturday afternoon with a business session at which the following officers were elected for the ensuing year.

President, Dr. Frank L. West, Utah Agricultural College, Logan, Utah.

First Vice-president, Professor Hyrum Schneider, University of Utah, Salt Lake City.

Second Vice-president, Professor Carl F. Eyring, Brigham Young University, Provo.

Secretary, A. O. Garrett, East High School, Salt Lake City.

Corresponding Secretary, C. Arthur Smith, East High School, Salt Lake City.

Councillors, Professor Harold R. Hage, University of Utah; Dr. M. C. Merrill, Utah Agricultural College, Logan; R. A. Hart, U. S. Reclamation Service, Salt Lake City.

Twenty-seven new members were added to the academy's roll of membership, making the largest increase in any one year in the history of the academy.

The academy roted unanimously to support the following resolutions:

Whereas: There is a greatly increased appreciation and use of the recreation and scenic resources of Utah to which an abundant supply of wild life is of great importance in furnishing an opportunity for nature study, fishing and hunting;

Whereas: The maintenance of proper forest conditions is necessary for the preservation and production of fish and game;

Wherras: Proper measures to insure a continued supply of fish and game must be based on a scientific knowledge of biological factors in. volved ;

Therefore, be it resolved, That the Utah Academy of Sciences:

1. Emphasize the close relationship between our forests and fish and game conservation.

2. Endorse the recognition by the Forest Service that the fish, game and wild life on the National Forests are valuable resources to be preserved and maintained.

3. Cooperate with the sportsmen, the State Game Department, and Federal departments in order that proper measures to perpetuate the fish and 